\title{
PERENCANAAN CHARGER CONTROLLER DAN BATERAI PADA PROTOTYPE PLTB SKALA KECIL DI TEKNIK LISTRIK POLINEMA
}

\author{
Wijaya Kusuma ${ }^{1}$, Anang Dasa Novfowan ${ }^{2}$, Abdul Manaf ${ }^{3}$, \\ Jurusan Teknik Elektro, Politeknik Negeri Malang \\ ${ }^{1}$ e-mail : wijayakusuma.polinema@gmail.com \\ (Artikel diterima: Oktober 2019, direvisi: September 2019, diterima untuk terbit: Januari 2020)
}

\begin{abstract}
Abstrak - One of the efforts to tackle the energy crisis is by reducing dependence on fossil energy sources and utilizing alternative energy. One of the alternative energy is wind energy. Wind energy can be used to make power plants. Wind power plant is a method to generate electrical energy by turning the wind turbine which connected to the generator, then the electrical energy which generated by generator used for supplying the load. However, the availability of the wind energy are not always constant in strength, thus to make this power plant work continuously to supplying the load it needed the element of electrical energy storage,that is battery.In order to make the electrical energy storage become efficient then used the component to support the battery charging, the presence of these component the energy produced can be stored optimallyand the battery life can be longer. The purpose of this study is to design and analyze the performance of the charger controller and battery in the PLTB system which is then used to support the work of the Wind Power Plant prototype system in State Polytechnic of Malang. The result of this study is how to choose the charger controller and battery based on some consideration, the characteristics of each components before and after be assembled in Wind Power Plant prototype system in State Polytechnic of Malang
\end{abstract}

Kata kunci: Alternative Energy , Wind Energy , Charger Controller, Battery

\section{Pendahuluan}

Energi listrik adalah bagian penting dalam kehidupan manusia,karena hampir semua aktivitas manusia selalu membutuhkan energi listrik. Di zaman yang semakin modern ini, kebutuhan energi listrik semakin meningkat, hal ini berbanding terbalik dengan jumlah energi yang tersedia saat ini. Di sisi lain, penggunaan bahan bakar fosil yang selama ini digunakan untuk membangkitkan energi listrik, seiring dengan berkembangnya jaman juga akan habis. Oleh karena itu, perlu adanya pemecahan masalah dari masalah tersebut, salah satunya adalah penggunaan energi alternatif untuk membangkitkan energi listrik

Pada penelitian ini akan menganalisa tentang perencanaan charger controller dan batere pada prototype PLTB skala kecil di Teknik Listrik POLINEMA.

\section{Tinjauan Pustaka}

\section{A. Potensi Angin di Indonesia}

Energi merupakan suatu kekuatan yang dimiliki oleh suatu zat sehingga zat tersebut mempunyai pengaruh pada keadaan sekitarnya.Menurut mediumnya dikenal banyak jenis energi.Salah satu dari berbagai jenis energi tersebut adalah energi angin. Perpindahan molekul udara memiliki energi kinetik, sehingga secara lokal jumlah molekul udara berpindah melalui luasan selama selang waktu tertentu menentukan besarnya daya.

Pada dasarnya angin terjadi karena ada perbedaan suhu antara udara panas dan udara dingin. Di daerah katulistiwa, udaranya menjadi panas mengembang dan menjadi ringan, naik ke atas dan bergerak ke daerah yang lebih dingin. Sebaliknya daerah kutub yang dingin, udaranya menjadi dingin dan turun ke bawah.Dengan demikian terjadi suatu perputaran udara berupa perpindahan udara dari kutub utara ke garis katulistiwa menyusuri permukaan bumi dan sebaliknya suatu perpindahan udara dari garis katulistiwa kembali ke kutub utara, melalui lapisan udara yang lebih tinggi.Angin dapat bergerak secara horizontal maupun vertikal dengan kecepatan yang dinamis dan fluktuatif.

Dalam sebuah presentasi yang diadakan sebuah perusahaan yang bernama WhyPgen dan Badan Pengkajian dan Penerapan Teknologi (BPPT) pada tanggal 14 Mei 2013 , Indonesia adalah salah satu negara yang memiliki potensi untuk mengembangkan pembangkit listrik tenaga angin. Potensi tenaga angin yang tersedia di Indonesia mencapai 9.286 MW akan tetapi sampai saat ini energi angin yang telah digunakan lebih kurang sebesar 2 MW (BMKG,2013).

Berikut ini akan ditampilkan peta prakiraan aliran dan kecepatan angin diseluruh Indonesia.

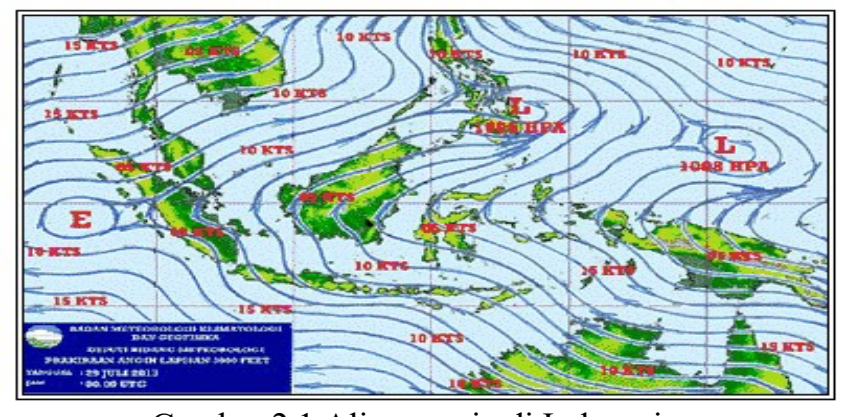

Gambar 2.1 Aliran angin di Indonesia

(Sumber:Said,2014)

Angin di wilayah Indonesia pada umumnya bergerak dari arah timur menuju arah barat daya dengan kecepatan angin antara $2.5 \mathrm{~m} / \mathrm{s}$ sampai dengan $7.5 \mathrm{~m} / \mathrm{s}$. Kecepatan angin $7.5 \mathrm{~m} / \mathrm{s}$ di Indonesia terdapat di daerah Samudera Hindia Selatan Jawa hingga Selatan Nusa Tenggara Timur, Laut Jawa, Laut Bali, Laut Banda, Laut Flores dan Perairan Selatan Merauke. 


\section{B. Energi Angin}

Energi angin merupakan energi yang berasal dari alam.Angin ini disebabkan karena karena adanya perbedaan suhu antara udara panas dan udara dingin.Di daerah panas, udaranya menjadi panas. Mengembang dan menjadi ringan, naik ke atas dan bergerak ke daerah yang dingin. udara menjadi dingin dan turun ke bawah. Dengan demikian terjadi suatu perputaran udara.Perpindahan inilah yang disebut sebagai angin. Sekarang ini, energi angin hanya memenuhi sebagian kecil saja dari kebutuhan energi.Dengan demikian kemajuan teknologi.Penggunaan energi angin makin meningkat dan biaya pekamaiannya semakin murah.

Daya P0 yang dikandung oleh angin dengan massa $m$, dalam volum silinder yang mempunyai luas $A$, dalam waktu $t$, dengan kerapatan udara $\rho$, dan volume silinder $V o$ adalah merupakan energi kinetik (Ek) angin dibagi waktu.

\section{Turbin Angin}

Turbin angin mengambil energi angin dengan menurunkan kecepatannya. Rotor harus terbuat dari piringan solid dan tidak berputar sama sekali, yang artinya tidak ada energi kinetik yang akan dikonversi. Energi angin bisa ditangkap dengan dua atau tiga buah baling-baling yang didesain seperti sayap pesawat terbang.Untuk mendapatkan kecepatan angin yang cukup tinggi, konstan, dan tidak terlalu banyak turbulensi biasanya turbin angin dipasang di atas sebuah menara pada ketinggian 30 meter atau lebih. Balingbaling yang digunakan berfungsi seperti sayap pesawat udara. Ketika angin bertiup melalui baling-baling tersebut, maka akan timbul udara bertekanan rendah di bagian bawah dari baling-baling,

Tekanan udara yang rendah akan menarik baling-baling bergerak ke area tersebut. Gaya yang ditimbulkan dinamakan gaya angkat. Besarnya gaya angkat biasanya lebih kuat dari gaya tarik. Kombinasi antara gaya angkat dan gaya tarik menyebabkan rotor berputar seperti propeler dan memutar generator. Turbin angin bisa digunakan secara stand-alone, atau bisa dihubungkan ke jaringan transmisi.

\section{Konstruksi Turbin Angin Secara Umum}

Secara umum turbin angin terduri dari rotor blade,gear box rotor diameter, fixed box dan fitch. Untuk bentuk dari bagian kontruksi tersebut dapat dilihat pada gambar 2.2 Kontruksi turbin angin.

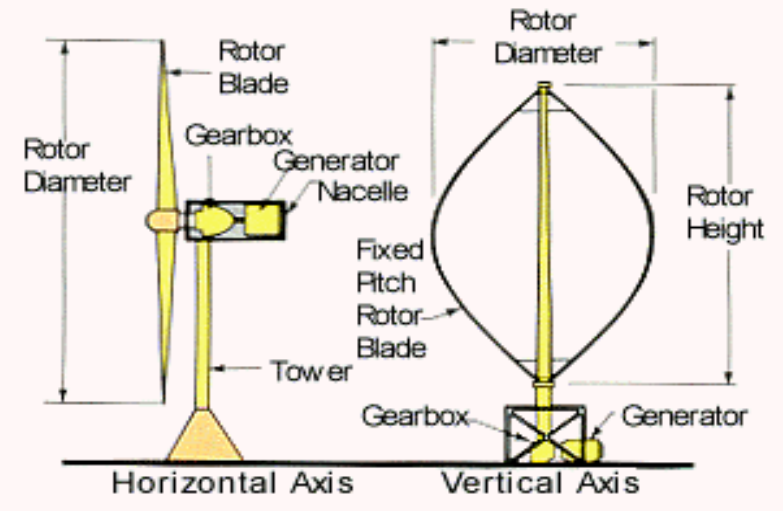

Wind Turbine Configurations

Gambar 2.2. Konstruksi Turbin Angin (Sumber:Burton, 2014)
E. Jenis Turbin Angin dikategorikan berdasarkan posisi sumbu

Turbin angin pada prinsipnya dapat dibedakan atas dua jenis turbin berdasarkan arah putarannya.Turbin angin yang berputar pada poros horisontal disebut dengan turbin angin poros horisontal atau Horizontal Axis Wind Turbine (HAWT), sementara yang berputar pada poros vertikal disebut dengan turbin angin poros vertikal atau Vertical Axis Wind Turbine (VAWT).
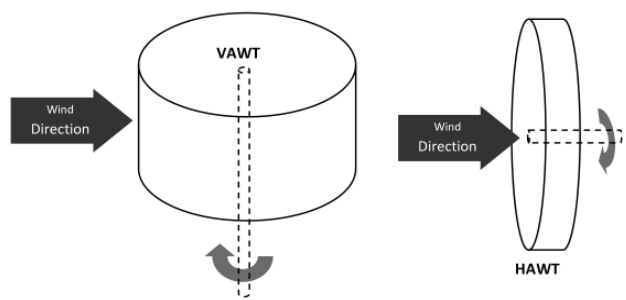

Gambar 2.3 Jenis turbin angin berdasakan sumbu (Sumber:Adaramola,2014)

\section{F. Generator}

Generator listrik adalah sebuah alat yang memproduksi energilistrik dari sumber energi mekanik, biasanya dengan menggunakan induksi elektromagnetik. Proses ini dikenal sebagai pembangkit listrik. Walau generator dan motor punya banyak persamaan, tapi motor adalah alat yang mengubah energi listrik menjadi energi mekanik. Generator mendorong muatan listrik untuk bergerak melalui sebuah sirkuit listrik eksternal, tapi generator tidak menciptakan listrik yang sudah ada di dalam kabel lilitannya.Hal ini bisa dianalogikan dengan sebuah pompa air, yang menciptakan aliran air tapi tidak menciptakan air di dalamnya. Sumber energi mekanik bisa berupa resiprokat maupun turbin mesin uap, air yang jatuh melalui sebuah turbin maupun kincir air, mesin pembakaran dalam, turbin angin, engkol tangan, energi surya atau matahari, udara yang dimampatkan, atau apa pun sumber energi mekanik yang lain.

Pada 1831-1832 Michael Faraday menemukan bahwa perbedaan potensial dihasilkan antara ujung-ujung konduktor listrik yang bergerak tegak lurus terhadap medan magnet. Dia membuat generator elektromagnetik pertama berdasarkan efek ini menggunakan cakram tembaga yang berputar antara kutub magnet tapal kuda. Proses ini menghasilkan arus searah yang kecil.

Desain alat yang dijuluki 'Cakram Faraday' itu tidak efisien dikarenakan oleh aliran arus listrik yang arahnya berlawanan di bagian cakram yang tidak terkena pengaruh medan magnet. Arus yang diinduksi langsung di bawah magnet akan mengalir kembali ke bagian cakram di luar pengaruh medan magnet. Arus balik itu membatasi tenaga yang dialirkan ke kawat penghantar dan menginduksi panas yang dihasilkan cakram tembaga. Generator homopolar yang dikembangkan selanjutnya menyelesaikan permasalahan ini dengan menggunakan sejumlah magnet yang disusun mengelilingi tepi cakram untuk mempertahankan efek medan magnet yang stabil. Kelemahan yang lain adalah amat kecilnya tegangan listrik yang dihasilkan alat ini, dikarenakan jalur arus tunggal yang melalui fluks magnetik.

\section{G. Permanen Magnet Generator}

Generator ini memiliki dua komponen utama, yaitu stator dan rotor yang menentukan jenis dan karakteristik 
generator.Stator adalah bagian dari generator yang statis (diam atau tidak berubah). Stator berfungsi sebagai kumparan jangkar yang menghasilkan listrik saat terpotong medan magnet dari rotor. Arus AC yang menuju ke beban disalurkan melalui stator.Rotor adalah bagian generator yang berputar. Rotor berfungsi sebagai kumparan medan untuk menghasilkan fluks. Digunakan dua buah rotor yang mengapit stator untuk menghasilkan fluks magnet. Untuk menghasilkan medan magnetik digunakan magnet permanen pada rotor yang dilekatkan pada piringan rotor. Dua buah rotor tersebut dihubungkan menggunakan suatu poros sebagai media putar. Antara rotor dan stator dipisahkan oleh celah udara (air gap). Jumlah kutub magnet yang digunakan untuk masing-masing piringan rotor dapat ditentukan menggunakan persamaan sebagai berikut (Zuhal, 1990) :

$$
\begin{aligned}
f=\frac{P}{2} x \frac{n}{60} & \\
& p=\frac{120 f}{n}
\end{aligned}
$$

dengan:

$$
\begin{aligned}
& n=\text { Kecepatan putar rotor }(\mathrm{rpm}) \\
& P=\text { Jumlah kutub rotor } \\
& f=\text { frekuensi }(\mathrm{Hz})
\end{aligned}
$$

Perputaran rotor akan memutar medan magnet yang dihasilkan oleh kumparan medan. Medan putar yang dihasilkan pada rotor akan diinduksikan pada kumparan jangkar sehingga pada kumparan jangkar yang terletak di stator akan menghasilkan fluks magnetik yang berubah-ubah besarnya terhadap waktu.Adanya perubahan fluks magnetik yang melingkupi suatu kumparan akan menimbulkanggl induksi pada akhir kumparan tersebut.

T.F. Chan,2007 melakukan penelitian untuk membuat generator sinkron magnet. Permanen axial fluks, dimana jenis generator ini cocok digunakan pada sistem pembangkit listrik tenaga bayu baik dengan turbin angin sumbu vertikal maupun turbin angin sumbu horizontal. Generator tersebut di rancang dengan desain rotor bagian luar yang dapat secara langsung dikopel atau dipasangkan dengan turbin angin, selain itu desain dari angker generator tanpa inti dapat menghilangkan daya tarik magnet antara bagian yang statis dengan bagian yang bergerak.Hal yang ditinjau dari desain dan konstruksi generator sinkron magnet permanen axial fluks ini adalah mempelajari laju kerapatan fluks magnet agar dapat memprediksi besanya nilai EMF.

Howey pada tahun 2009 telah melakukan penelitian tentang generator listrik yaitu generator magnet permanen aksial yang diaplikasikan pada Pembangkit Listrik Tenaga Piko-Hidro (PLTPH).Daya Piko Hidro sangat baik dan memiliki biaya murah untuk memproduksi listrik di negara berkembang, tetapi masih ada beberapa hal yang dapat dikembangkan dari segi performansinya.Generator magnet permanen aksial banyak digunakan pada beberapa jenis mesin listrik untuk turbin bayu namun masih sedikit diaplikasikan pada PLTB. Sehingga D.A. Howey melakukan penelitian penggunaan Generator Magnet Permanen Aksial pada PLTPH dapat memproduksi listrik lebih besar dari sekitar $90 \%$ efisiensi lebih besar dari menggunakan generator sinkron dengan efisiensi sebesar $75 \%$.

permanen pada konstruksi mesin listrik ini adalah :

Tidak ada energi yang diserap sistemmedan eksitasi sehingga tidak adakerugian eksitasi yang artinya dapat meningkatkan efisiensi.
Menghasilkan torsi yang lebih besar daripada menggunakan eksitasi elektromagnet.

- Menghasilkan performa dinamis yang lebih besar (kerapatan fluks magnet lebih besar pada celah udara) dibandingkan dengan menggunakan eksitasi.

- Menyederhanakan konstruksi dan perawatan.

- Mengurangi biaya pemeliharaan pada beberapa tipe mesin.

Pada mesin fluks aksial ini ada beberapadesain, antara lain adalah :

- Mesin Sisi Ganda Rotor Tunggal

- Mesin Sisi Ganda Stator Tunggal

- Mesin Tunggal

- Mesin Sisi Ganda Tanpa Besi

- Mesin Sisi Banyak

\section{H. Batere (Battery)}

Battery adalah peralatan untuk menyimpan energi. Jenis battery saat ini digunakan untuk kebutuhan PLTS adalah

$\begin{array}{ll}\text { - } & \text { AGM battery, Deep Cycle VRLA } \\ \text { - } & \text { GEL Battery } \\ \text { - } & \text { Lithium }\end{array}$

Jenis battery berdasarkan tegangan listrik, yang sering digunakan dalam PLTS

\section{- Battery dengan tegangan $12 \mathrm{~V}$ \\ - Battery dengan tegangan $2 \mathrm{~V}$}

Pada penelitian ini menggunakan batere jenis VRLAGEL dengan DOD $40 \%$

\section{Kontroler Pengisian Baterai PLTB}

Charge Controlleradalah rangkaian elektronik yang mengatur proses pengisian aki atau rangkaian aki (Battery Bank). Tegangan AC yang dihasilkan oleh PLTB umumnya bervariasi 12 volt ke-atas.Kontroler ini berfungsi sebagai alat pengatur tegangan aki agar tidak melampaui batas toleransi dayanya. Disamping itu, alat pengontrol ini juga mencegah pengaliran arus dari aki mengalir balik ke generator ketika proses pengisian sedang tidak berlangsung (misalnya pada malam hari) sehingga aki yang sudah dicas tidak terkuras tenaganya. Apabila aki atau rangkaian aki sudah penuh terisi, maka aliran AC dari generator akan diputuskan agar aki itu tidak lagi menjalani pnngisian sehingga pengerusakan terhadap baterai bisa dicegah dan usia aki bisa diperpanjang. Pengendalian proses pengisian aki dengan membuka dan menutup aliran arus AC dari generator ke aki adalah fungsi yang paling dasar sebuah charger controller.

\section{J. Prinsip Kerja Charger Controller}

Saat tegangan pengisian di baterai telah mencapai keadaan penuh, maka controller akan menghentikan arus listrik yang masuk ke dalam baterai untuk mencegah over charge. Dengan demikian ketahanan baterai akan jauh lebih tahan lama. Di dalam kondisi ini, listrik yang tersuplai dari generator akan langsung diteruskan ke beban/peralatan listrik dalam jumlah tertentu sesuai dengan konsumsi daya beban peralatan listrik.

Saat tegangan di baterai dalam keadaan hampir kosong, maka controller berfungsi menghentikan pengambilan arus 
listrik dari baterai oleh beban peralatan listrik. Dalam kondisi tegangan tertentu (misal umumnya sekitar 10\% sisategangan di baterai), maka pemutusan arus beban dilakukan oleh kontroler. Hal ini menjaga baterai dan mencegah kerusakan pada sel - sel baterai. Pada kebanyakan model charger controller, indikator lampu akan menyala dengan warna tertentu (umumnya berwarna merah atau kuning) yang menunjukkan bahwa baterai dalam proses charging. Dalam kondisi ini, bila sisa arus di baterai kosong (dibawah 10\%), maka pengambilan arus listrik dari baterai akan diputus oleh charger controller, maka peralatan listrik / beban tidak dapat beroperasi.

Pada kontroler tipe - tipe tertentu dilengkapi dengan digital meter dengan indikator yang lebih lengkap, untuk memonitor berbagai macam kondisi yang terjadi pada sistem PLTB dapat terdeteksi dengan baik. Chargercontroller adalah komponen penting dalam Pembangkit Listrik Tenaga Bayu. Cara kerja antara lain: (a) Charging Mode dan (b) Mode Operasi Charge Controller

\section{Metoda Penelitian}

\section{A. Tempat dan Waktu Penelitian}

Pelaksanaan penelitian ini dilakukan di Laboratorium Analog dan Digital Program Studi Teknik Listrik ,Jurusan Teknik Elektro Politeknik Negeri Malang ,kampus II,Jl. Sukarno Hatta No. 9 Malang dan dilaksanakan mulai 1April 2019 sampai 31 Oktober 2019. Dari data - data yang telah didapatkan, maka kita bisa mulai melakukan analisis penggunaan charger control untuk pengisian battery

\section{B. Langkah-langkah pengolahan data}

Sistematika pelaksanaan dari tahap persiapan sampai selesai dijelaskan dalam bagan alir dibawah ini :

Berikut adalah penjelasan dari diagram alir penelitian :

1. Pengerjaan Penelitian dimulai dengan mengajukan judul "Perencanaan charger controller dan Batere pada prototype PLTB skala kecil di Teknik Listrik POLINEMA"

2. Langkah kedua yaitu studi literatur dengan cara mencari referensi yang berupa buku / E-Book, Jurnal penelitian yang sudah ada yang berkaitan judul Penelitian yang akan diangkat.

3. Langkah ketiga yaitu melakukan observasi untuk mengetahui kondisi di lapangan.

4. Langkah keempat yaitu melakukan wawancara untuk mendapatkan informasi lebih dalam guna memperdalam pemahaman terhadap pembahasan yang diangkat.

5. Langkah kelima yaitu merencanakan kapasitas baterai yang akan digunakan berdasarkan perhitungan dengan data yang dikumpulkan.

6. Langkah keenam yaitu memilih baterai berdasarkan perhitungan sebelumnya dan berdasarkan barang yang tersedia di pasaran.

7. Langkah ketujuh yaitu merencanakan spesifikasi charger controller yang akan di pilih sesuai dengan datadata yang ada.

8. Langkah kedelapan yaitu memilih charger controller berdasarkan spesifikasi yang telah direncanakan dan berdasarkan barang yang tersedia di pasaran.

9. Langkah kesembilan yaitu melakukan pengujian charger controller dan juga baterai untuk melakukan analisa kondisi dan kinerja peralatan tersebut, sebelum di aplikasikan pada prototype PLTB skala kecil, apabila peralatan tidak dapat dipasang pada sistem, maka dilakukan pemilihan peralatan kembali.

10. Langkah kesepuluh yaitu memasang charger controller dan baterai pada sistem dan melakukan analisa terhadap kondisi dan kinerja alat.

11. Penulisan Hasil Penelitian yang dilakukan.

12. Selesai.

\section{HASIL ANALISA DAN PEMBAHASAN}

\section{A. 4.1.Prinsip kerja PLTB}

Pemanfaatan energi alternatif yaitu angin, yang digunakan untuk memutar kincir angin atau turbin yang di kopel dengan generator, sehingga apabila turbin angin berputar maka generator pun ikut berputar. Putaran generator inilah yang akan mengkonversi energi mekanik menjadi energi listrik. Kemudian tegangan listrik perlu di stabilkan dengan converter DC - DC dengan tujuan untuk mengatur tegangan charging agar stabil sesuai kebutuhan peralatan kontrol setelah proses ini. Tegangan ini juga yang nantinya akan menuju ke beban. Tetapi alur energi tidak bisa terus menerus di suplai dari pembangkit dikarenakan kekuatan angin untuk memutar turbin yang tidak menentu. Untuk itu diperlukan adanya baterai yang dapat digunakan sebagai penyimpan energi dari pembangkit yang kemudian akan digunakan saat turbin tidak berputar dengan stabil bahkan saat berhenti. Baterai disini dilengkapi dengan charger controlleryang bertujuan untuk menjaga baterai agar tidak over-charge atau over-discharge. Dalam sistem prototype PLTB ini dirancang untuk menyuplai dua jenis beban, yaitu beban DC dan beban AC. Untuk beban AC, output dari terminal charger controlleryang akan menuju ke beban akan melalui inverter terlebih dahulu sebelum digunakan. Inverter ini bertujuan merubah tegangan $12 \mathrm{~V}$ DC menjadi $220 \mathrm{~V}$ AC.

\section{B. SpesifikasiPeralatan System}

Berikut merupakan spesifikasi peralatan-peralatan yang digunakan pada prototype PLTB skala kecil di Polinema :

\section{Turbin Angin}

Tipe

Bahan

Daya (P)

Kec.Putaran

Diameter

Tinggi

Jumlah blade

Generator

Tipe

Daya $(\mathrm{P})$

Tegangan (V)

Kec.Putaran

Jumlah Magnet

Tipe Magnet

Jumlah coil

Diameter

Frekuensi

Pole (Kutub)

: Vertical Axis Savonius

: Aluminium $\left(0.271 \mathrm{~kg} / \mathrm{cm}^{2} / \mathrm{m}\right)$

: 100 Watt

: $65 \mathrm{rpm}$ : 1 meter

$: 1,4$ meter

: 3 buah

: Axial Magnet Permanent

: 55 Watt

: 20 Volt

: $500 \mathrm{rpm}$

: 24 buah

: Magnet Permanen Neodymium N 52

: $18 ; 0,5 \mathrm{~mm}^{3}$

: $50 \mathrm{~Hz}$
$: \pm 30 \mathrm{~cm}$

\section{Inverter:}




\begin{tabular}{|c|c|c|c|}
\hline \multicolumn{4}{|c|}{ Input DC Current $\quad: 30 \mathrm{~A}$} \\
\hline \multicolumn{4}{|c|}{ V Input $\quad: 9,5 \mathrm{~V}-16 \mathrm{~V}$} \\
\hline Output AC Voltage & \multicolumn{3}{|l|}{$: 230 \mathrm{~V}$} \\
\hline Surja Power & \multicolumn{3}{|l|}{ : 600 watt } \\
\hline $\begin{array}{l}\text { Frekuensi } \\
\text { selectable) }\end{array}$ & $50 / 60$ & $\mathrm{~Hz}$ & $\pm 3 \%$ (switch \\
\hline Dimensi $(1 \mathrm{x}$ w x h) & \multicolumn{3}{|c|}{$: 260 \times 129 \times 82,5 \mathrm{~mm}$} \\
\hline Efficiency & \multicolumn{3}{|l|}{$:>87 \%$} \\
\hline Daya $(\mathrm{P})$ & \multicolumn{3}{|c|}{ : 300 Watt } \\
\hline Input DC Current & \multicolumn{3}{|l|}{$: 30 \mathrm{~A}$} \\
\hline V Input $\quad: 9$ & \multicolumn{3}{|c|}{$: 9,5 \mathrm{~V}-16 \mathrm{~V}$} \\
\hline Output AC Voltage & \multicolumn{3}{|l|}{$: 230 \mathrm{~V}$} \\
\hline Surja Power & \multicolumn{3}{|l|}{ : 600 watt } \\
\hline $\begin{array}{l}\text { Frekuensi } \\
\text { selectable) }\end{array}$ & $: \quad 50 / 60$ & $\mathrm{~Hz}$ & $\pm 3 \%$ (switch \\
\hline Dimensi ( 1 x w x h) & \multicolumn{3}{|c|}{$: 260 \times 129 \times 82,5 \mathrm{~mm}$} \\
\hline Efficiency & \multicolumn{3}{|l|}{$:>87 \%$} \\
\hline Daya $(\mathrm{P})$ & \multicolumn{3}{|c|}{ : 300 Watt } \\
\hline
\end{tabular}

\section{Pengujian Charger Controller}

Pengujian charger controller di lakukan dengan menggunakan sumber powerpack DC yang berada di laboratorium elektronika daya Politeknik Negeri Malang gedung AL.Pengujian ini bertujuan untuk mengetahui karakteristik dari charger controller tersebut.

\section{Gambar Rangkaian Percobaan}

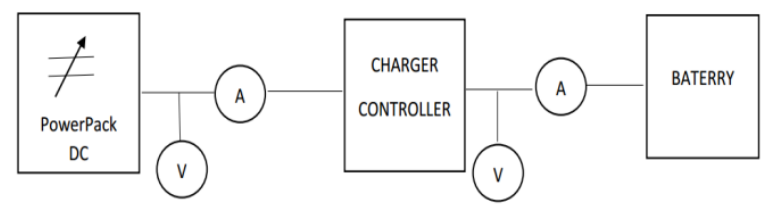

\section{Prosedur Pengujian Alat}

- Sebelum melakukan pengujian, pas emua rangkaian terpasang dengan benar sesuai dengan gambar rangkaian.

- Pastikan baterai dalam keadaan low atau habis.

- Kemudian mulai dinyalakan sumber dari powerpack DC dengan rating 0-20 Vdc $20 \mathrm{~A}$. Dan mulai untuk memasukkan variabel tegangan sampai didapatkan nilai tegangan yang dapat digunakan untuk suplai charger controller.

- Lakukan pencatatan setiap perubahan tegangan input dari powerpack DC untuk mendapatkan hasil akurat pada tegangan berapa charger controller dapat menyala.

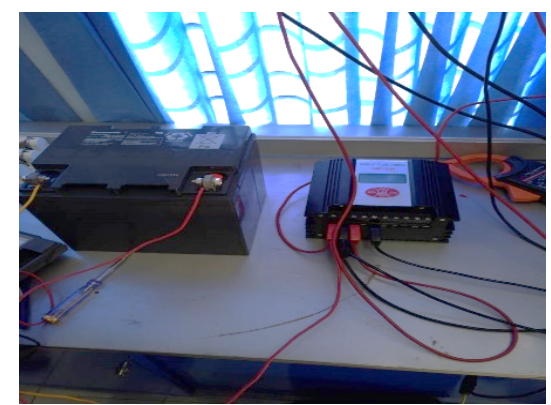

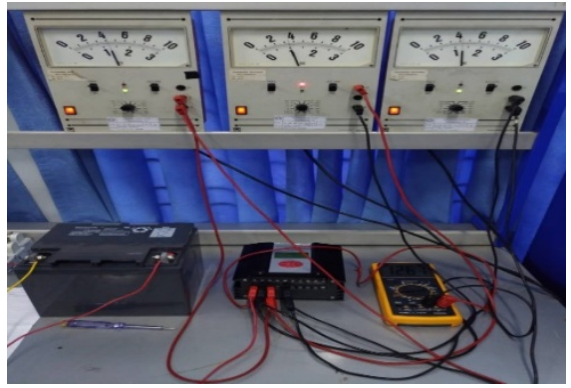

Gambar 4.1 Pengujian Penggunaan Alat Chager Controller.

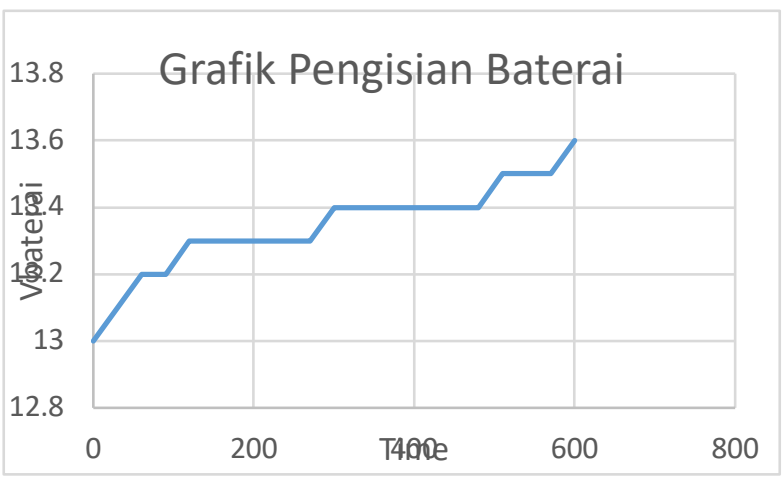

\section{Pengujian Charging Baterai pada Sistem PLTB}

Pengujian pengisian baterai dan pengujian kinerja charger controller pada sistem PLTB dilakukan dengan menggabungkan seluruh komponen untuk mengetahui dan menganalisa kemampuan serta kinerja alat sesuai dengan spesifikasi yang ada pada masing-masing alat.

Pada pengujian ini bertujuan untuk mengetahui arus charging sistem dengan kecepatan angin yang bervariasi. Dalam percobaan ini komponen yang digunakan adalah Turbin, Generator, Charger Controller dan Baterai.

\section{KeSimpUlan DaN SARAN}

\section{A. Kesimpulan}

Dari hasil penelitian dan pengujian alat, mulai pengambilan data sampai analisa hasil percobaan yang dilakukan dilapangan, maka dapat diambil kesimpulan sebagai berikut :

1. Berdasarkan hasil perhitungan dan perencanaan, maka batere yang dipilih adalah type VRLA - GEL dengan kapasitas $42 \mathrm{AH}$, dengan $\mathrm{DOD}=40 \%$ sesuai yang ada dipasaran.Dan dari hasil percobaan yang dilakukan dengan beban 23 Watt selama 8 jam 42 menit, sesuai DOD yaitu discharging $40 \%$ sehingga pemilihan batere baik dan benar.

2. Setelah dilakukan pengujian, diketahui bahwa charger controller melakukan pemutusan

input charging ketika tegangan 14,5 Volt dan melakukan pemutusan discharging ketika tegangan baterai mencapai 10,8 Volt, hal tersebut sesuai dengan yang tertera pada manual user charger controller tersebut, sehingga dapat dikatakan charger controller bekerja dengan baik.

3. PLTB yang digunakan yaitu type Vertical Axis Savonius dengan jumlah blade 3 buah, Daya 100 Watt dan 
Generator Axial Magnet Permanent 55 Watt, ternyata mulai bisa charging pada kecepatan angin 2,6 m/s. Dan dari hasil percobaan dilingkungan POLINEMA, maka pemasangan PLTB tersebut cocok dipasang pada gedung bertingkat seperti yang kami lakukan pada gedung Teknik Sipil lantai 7 dengan kecepatan angin antara 4 sampai $7,2 \mathrm{~m} / \mathrm{s}$, sehingga dapat mesuplai daya rata-rata 41,8 Watt yaitu $76 \%$ dari Daya generatornya, selama 7 sampai 8 jam perharinya.

\section{B. 5.2.Saran}

Kami menyarankan untuk penggunaan PLTB yang menggunakan turbin type vertical Axis Savonius dengan jumlah blade 3 buah, sebaiknya digunakan pada daerah dengan kecepatan angin diatas $2,6 \mathrm{~m} / \mathrm{s}$, untuk daerah sekitar polinema sebaiknya pada gedung bertingkat seperti yang kita lakukan yaitu diatas gedung Teknik Sipil lantai 8.

\section{DAFTAR PUSTAKA}

[1] Boylestad. Nashelsky, Electronic Device \& Circuit Theory Industrial Solid State Electronics

[2] Milman Halkias, Elektronika TerpadunI dan II , Jakarta 1986.

[3] Horowitz p, Seni dan desain elektronika, Multi Gramedia. Jakarta.

[4] G J Ritche, Transistor Circuit Techniques. Elektronika Industri .Com

[5] Owen Bishop, Published by Elsevier Ltd, Electronics A First Course, second edition 2006

[6] Passive Electronic components, down loaded from Digital Engineering Library,MGraw Hill Companies, 2004.

[7] Practical design Techniques for sensor signal conditioning, Published by pentice Hall

[8] Ian R Sinclair and John Dunton, Practical Electronics Handbook, sixth edition 2007, Published by Elsevier Ltd.

[9] James F. Lowe, Electronics for Electrical Trades, $4^{\text {th }}$ edition,McGraw-Hill Book Company Australia Pty Ltd, Sydney, NSW, 1997 